\title{
Procesos naturales y antropogénicos asociados al evento de mortali- dad de conchas de abanico ocurrido en la bahía de Paracas (Pisco, Perú) en junio del 2000 *
}

\section{Natural and anthropogenic processes associated to scallops mortality in Paracas bay (Pisco, Peru) in june 2000}

\author{
Rita Cabello $^{1 * *}$, Jorge Tam $^{2}$, Maria Elena Jacinto ${ }^{3}$
}

\section{Resumen}

Con la finalidad de determinar los procesos que desencadenaron el evento de mortalidad de concha de abanico (Argopecten purpuratus) el 6 de junio del 2000, se analizaron las condiciones ambientales naturales y antropogénicas en la Bahía de Paracas (Pisco, Perú) durante el período de actividad pesquera industrial pesquera, entre el 17 de mayo y el 13 de junio del 2000.

Se evaluaron diariamente las variables oceanográficas de temperatura, oxígeno disuelto, volumen de fitoplancton y variables de calidad acuática, aceites y grasas, sólidos suspendidos totales, $\mathrm{DBO}_{5}, \mathrm{pH}$, sulfuros y coliformes termotolerantes, en 5 estaciones de la Bahía de Paracas.

Desde mediados de mayo, se registraron altos contenidos de aceites y grasas provenientes de efluentes pesqueros. A fines de mayo se observó la presencia de una marea roja asociada a un incremento en los sólidos suspendidos totales, $\mathrm{pH}$ y oxígeno disuelto, especialmente frente a Atenas y El Chaco. A inicios de junio en superficie se produjo una disminución de los sólidos suspendidos totales $\left(<25 \mathrm{mg}^{\left.-\mathrm{L}^{-1}\right)}\right.$ y oxígeno $\left(<3 \mathrm{~mL} . \mathrm{L}^{-1}\right)$, llegando a un máximo las concentraciones de grasa (máx.: $10,1 \mathrm{mg} \cdot \mathrm{L}^{-1}$ ), mientras que en los fondos el proceso acumulativo de carga orgánica produjo un estado anóxico con alto contenido de sulfuros (máx.: 19,73 g-at. $\mathrm{L}^{-1}$ ). Estas condiciones redujeron la calidad del ambiente marino, y produjeron la mortalidad de los organismos bentónicos.

El aporte de materia orgánica proveniente de efluentes pesqueros, junto con el aporte proveniente de la floración algal nociva, ejerció un efecto sinérgico negativo sobre la calidad de la columna de agua y los sedimentos, lo que provocó la mortalidad de especies bentónicas, entre ellas la concha de abanico.

Palabras clave: Contaminación marina, efluentes pesqueros, mortalidad, Argopecten purpuratus, Pisco, Perú.

\section{Abstract}

With the aim to determine the processes which generated the scallop (Argopecten purpuratus) mortality event on June 6, 2000, natural and anthropogenic environmental conditions in Paracas bay (Pisco, Perú) during a period of fishery industrial activity were analysed between May 17 and June 13, 2000.

Daily surveys of oceanographic variables such as temperature, oxygen, phytoplankton volume and aquatic quality variables such as oil and greases, total suspended solids, $\mathrm{BOD}_{5}, \mathrm{pH}$, sulphurs and thermotolerant coliforms, were carried out in 5 stations inside Paracas bay.

Since mid of May, high contents of oil and greases coming from fishery effluents were detected. At the end of May, the presence of a red tide was observed associated with an increase in total suspended solids, $\mathrm{pH}$ and dissolved oxygen, especially off Atenas and El Chaco. Beginning June in surface

${ }^{1,3}$ Línea de Investigación en Monitoreo Ambiental, Instituto del Mar del Perú (IMARPE), Apdo. 22, Callao, Perú.

2 Centro de Investigaciones en Modelaje Oceanográfico y Biológico Pesquero. Apdo. 22, Callao, Perú.

* Este estudio forma parte del Programa de Monitoreo Ambiental de la calidad acuática del medio marino en la Bahía de Paracas (Pisco, Perú) que el IMARPE realiza en forma permanente a través del Laboratorio Costero de Pisco.

**r rcabellot@hotmail.com. 
waters, a reduction in total suspended solids $\left(<25 \mathrm{mg} \cdot \mathrm{L}^{-1}\right)$ and oxygen $\left(<3 \mathrm{~mL} \cdot \mathrm{L}^{-1}\right)$ was produced, reaching a maximum the oil and greases (max: 10,1 mg. $\mathrm{L}^{-1}$ ), while in bottom waters the process of accumulation of organic matter produced an anoxic state with high sulphurs content (max: 19,73 gat. $L^{-1}$ ). These conditions reduced the quality of the marine environment, producing the mortality of the benthic organisms.

The input of organic matter coming from fishery effluents, together with the input coming from the harmful algal bloom, generated a synergic effect on the quality of the water column and the sediments producing the mortality of benthic species, among them, the scallops.

Keywords: Marine pollution, fishery effluents, mortality, Argopecten purpuratus, Pisco, Perú.

\section{Introducción}

La zona costera de la bahía de Paracas alberga áreas protegidas, residencias privadas y turísticas, puertos, caleta artesanal, centros de maricultura y plantas pesqueras. En el pasado se han registrado eventos de mortalidad de peces y organismos bentónicos, que en particular para los peces fueron denominados "varazones", atribuidos a las actividades antropogénicas y a las características naturales de la bahía. La mayoría de las investigaciones que han tratado de relacionar los eventos de mortalidad y las condiciones ambientales han sido hechas posteriormente (Grados et al. 1994, Jacinto et al. 1996), lo que imposibilita conocer la secuencia de cambios gene-

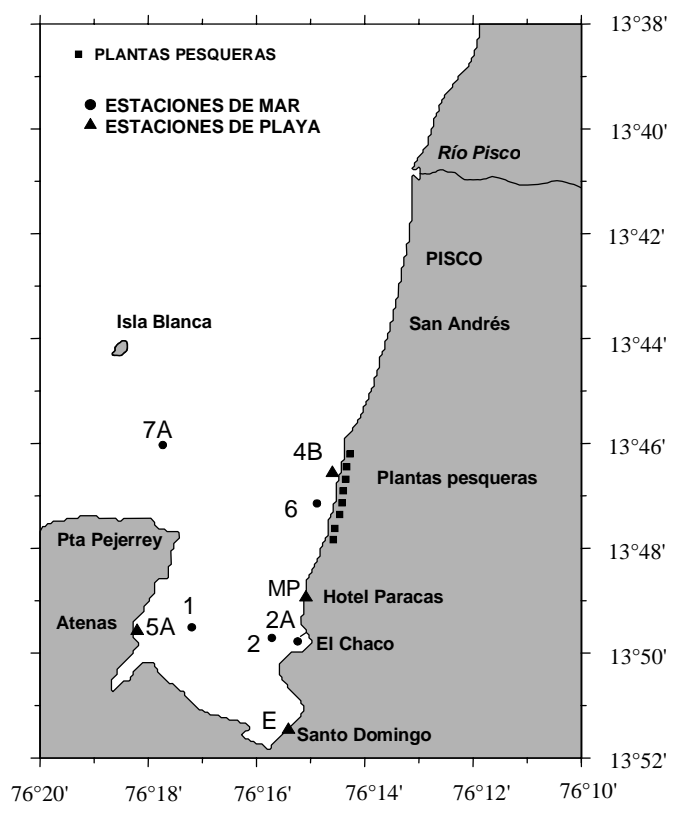

Figura 1. Ubicación de las estaciones de monitoreo en la Bahía de Paracas (Pisco, Perú). radores de estos eventos. Este hecho ha impedido la implementación de medidas preventivas de protección ambiental, ya que se requiere un conocimiento del origen y mecanismos de evolución de las variables involucradas tanto en cambios temporales como espaciales previos a estos eventos de mortalidad masiva.

Para lograr este conocimiento el IMARPE puso en marcha el Programa de Monitoreo de la Calidad Ambiental del Laboratorio Costero de Pisco-IMARPE, que se viene realizando de manera permanente en la bahía de Paracas desde mayo de 1999. Esto permitió contar con una vasta e importante información sobre la variabilidad de las condiciones ambientales previas y posteriores al evento de mortalidad de concha de abanico ocurrido el 6 de junio de 2000 (del 17 de mayo al 13 de junio), información que es analizada en el presente trabajo.

El objetivo del presente estudio es describir los eventos naturales y antropogénicos antes, durante y después de la mortalidad observada, mediante el análisis de la dinámica espacio-temporal de las variables de calidad acuática y oceanografía que permitan establecer un esquema de relaciones causales entre las variables estudiadas.

\section{Material y métodos}

Se analizaron los datos del 17 de mayo al 13 de junio de 2000 del Programa de Monitoreo diario del área costera de Paracas, Pisco (ver Tabla 1). Las 5 estaciones consideradas fueron (Fig. 1): frente a la playa Atenas (Est. 1), frente a la playa El Chaco a $0,5 \mathrm{~km}$ (Est. 2A) y a 1,5 $\mathrm{km}$ (Est. 2), frente a las plantas pesqueras (Est. 6) y al norte de Punta Pejerrey (Est. 7A). 
Además, con el fin de evaluar la calidad acuática para usos recreacionales, se realizó una evaluación en la zona de playa en 4 estaciones siguiendo la línea costera: en playa Atenas (Est $5 \mathrm{~A}$ ), en el muelle de las plantas pesqueras (Est. 4B), en el muelle del hotel Paracas (Est. MP) y en la playa Santo Domingo (Est. E).

Los muestreos se realizaron durante las mañanas, entre las 9:00 y las 13:00. El muestreo de agua de mar a nivel superficial se realizó con un balde plástico, y el muestreo de agua a $1 \mathrm{~m}$ del fondo se realizó con una botella Niskin de 5 L con termómetro de inversión. El muestreo de fitoplancton se realizó con una red estándar de $75 \mathrm{~mm}$ de poro.

Los parámetros de calidad acuática analizados fueron la temperatura, el oxígeno disuelto, el $\mathrm{pH}$, los sulfuros, los sólidos suspendidos totales (SST), los aceites y grasas, la demanda bioquímica de oxígeno $\left(\mathrm{DBO}_{5}\right)$ y los coliformes termotolerantes. Los análisis microbiológicos se realizaron en una sola oportunidad con el fin de evaluar la influencia de descargas domésticas.

Los análisis se realizaron siguiendo los siguientes métodos:

-Método titulométrico de Winkler modificado por Carpenter para la determinación de oxígeno (Grasshoff, 1999).

-Método gravimétrico 2540-D, para la determinación de sólidos suspendidos totales (APHA-AWWA-WPCF, 1999).

-Método colorimétrico de Fonselius para la determinación de sulfuro de hidrógeno (Grasshoff, 1999).

-Método potenciométrico por medio de un potenciómetro HANNA HI 9023 C para la determinación del $\mathrm{pH}$.

-Método gravimétrico para la determinación de aceites y grasas (Environmental Laboratory Water Resources Service, 1976).

-Método International Standard ISO 5815 para la determinación de Demanda Bioquímica de Oxígeno (ISO, 1983).
- Método de fermentación en tubos múltiples $(\mathrm{NMP}=$ número más probable) para la determinación de coliformes termotolerantes (APHA-AWWA-WPCF, 1999). Los coliformes termotolerantes son aquellos de origen fecal (de intestinos de animales de sangre caliente).

-Método volumétrico para la determinación de volumen de fitoplancton (Sournia 1978).

\section{Análisis de datos}

Con el fin de analizar la variación temporal en toda la bahía, para cada fecha se promediaron los datos de las estaciones de muestreo.

Para analizar la distribución espacial de las variables se graficaron isolíneas de magnitud de las variables, usando el método de grillado krigging puntual, con un modelo de variograma lineal isotrópico. Este método permite acentuar los gradientes espaciales de las variables (GS 1999).

\section{Resultados y discusión}

\section{Industria harinera}

Después de un período de veda, la producción de harina de pescado se inició el 6 de mayo con valores usualmente mayores a 10000 ton diarias (Fig. 2), y fue suspendida del 27 al 31 de mayo, para luego reiniciarse el 1 de junio, día en que se registró una pequeña varazón de peces frente al hotel Paracas, lo que indicaba ya la presencia de condiciones ambientales adversas en la bahía.

\section{Temperatura}

El año 2000 se caracterizó por presentar condiciones "normales" con Aguas Costeras Frías (ACF), cuya presencia fue confirmada por la aparición del dinoflagelado Protoperidinium obtusum, común en toda el área evaluada (Laboratorio Costero Pisco 2000a).

Los promedios mensuales superficiales obtenidos en mayo $\left(20,9^{\circ} \mathrm{C}\right)$ y junio $\left(20,1^{\circ} \mathrm{C}\right)$ indicaron un enfriamiento de las aguas al pasar de la estación de verano a otoño (Fig. 3), coincidente con un alejamiento de masas de aguas oceánicas. Sin embargo, los promedios 


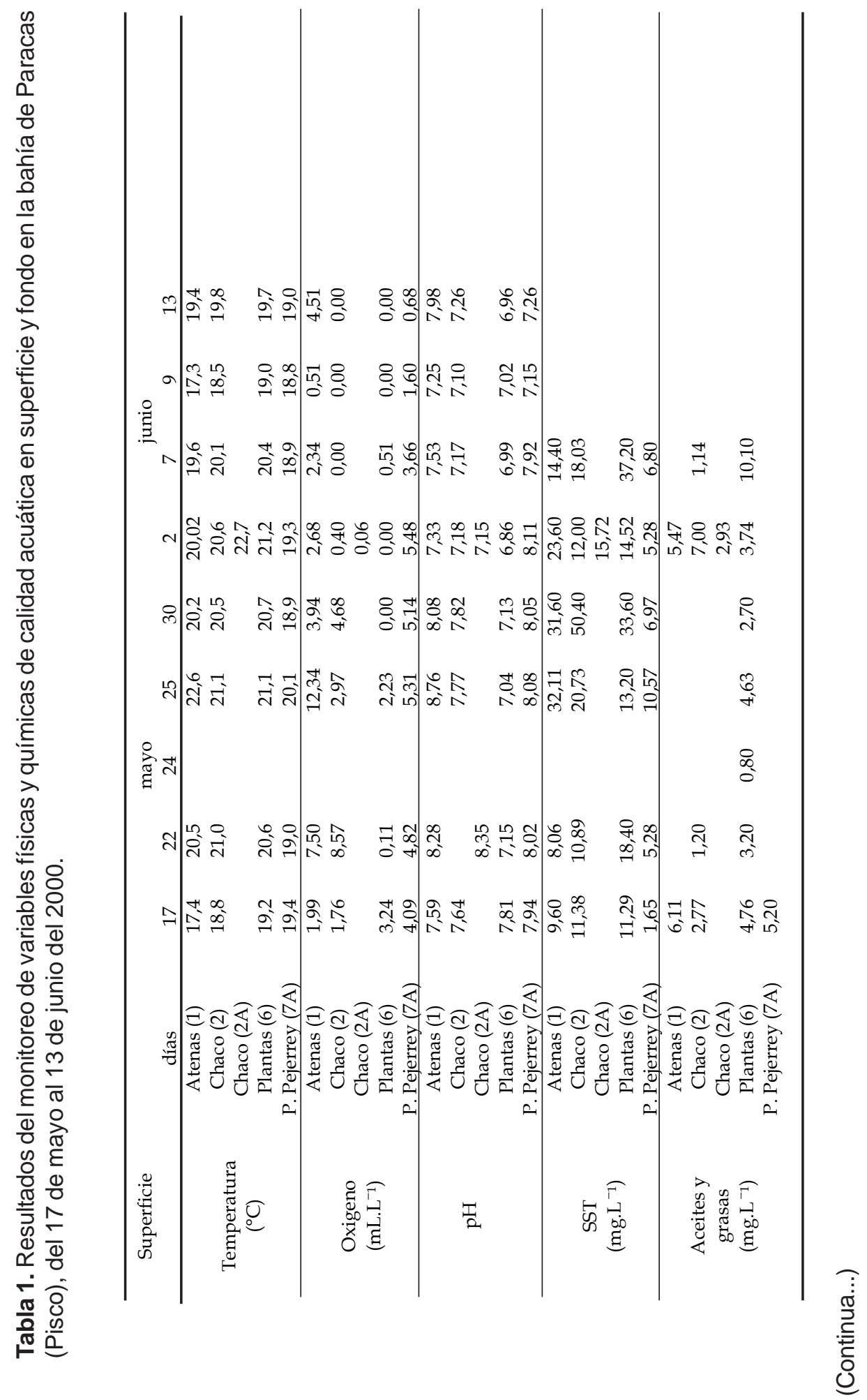




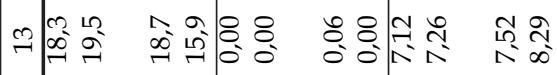

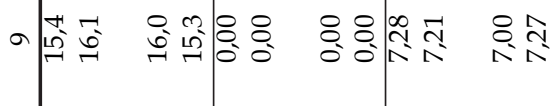

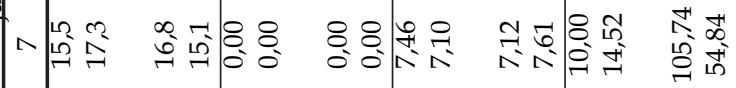

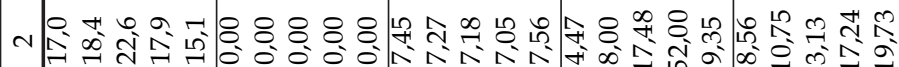

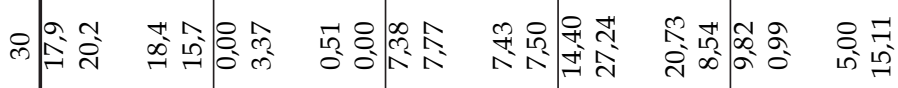

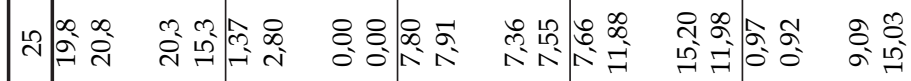

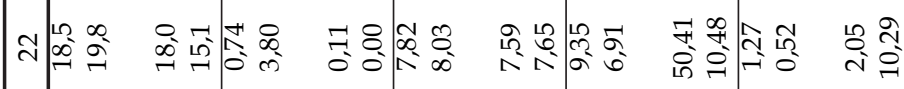

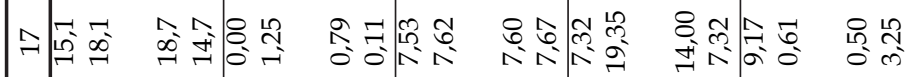

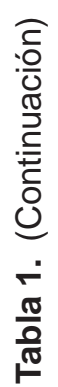

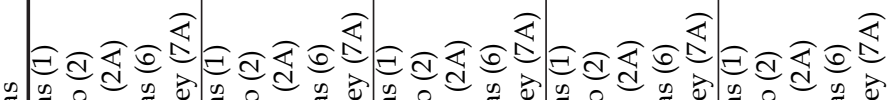

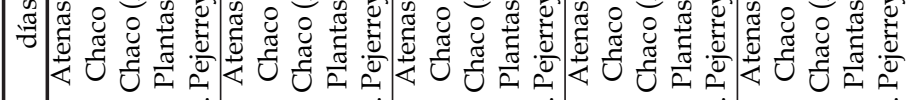




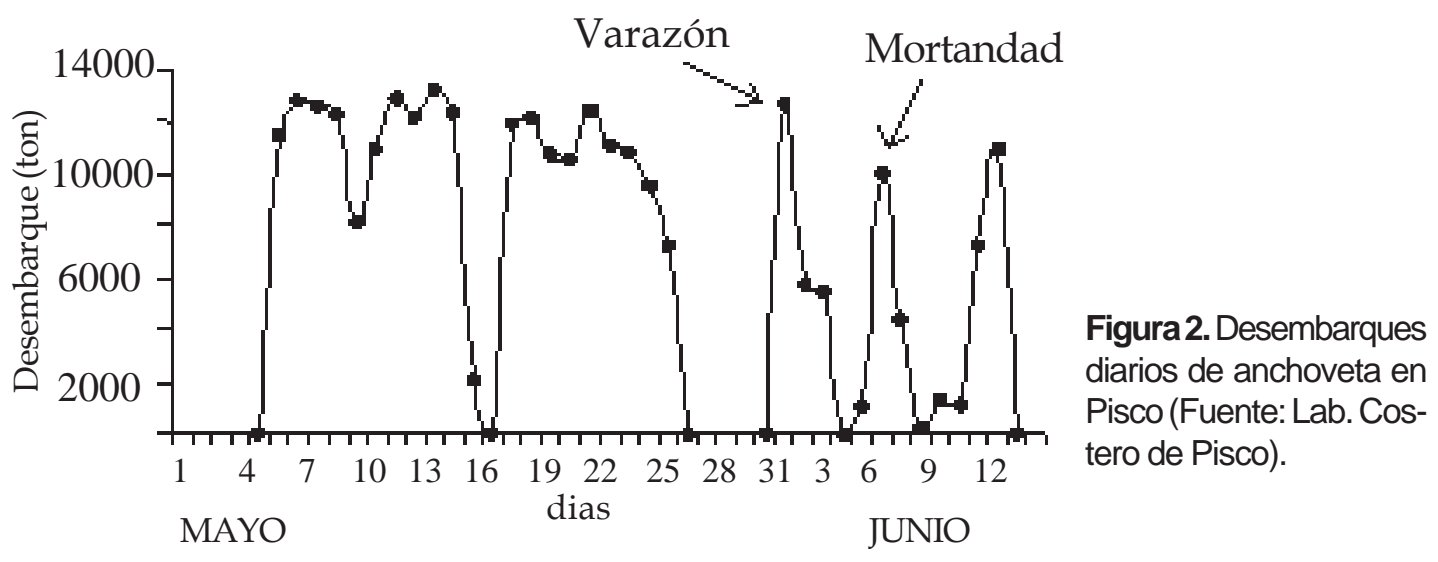

diarios obtenidos durante la segunda quincena de mayo muestran un incremento local de la temperatura, el 17 de mayo promedió $18,7^{\circ} \mathrm{C}$ y después del 2 de junio la temperatura promedió entre $20,08^{\circ} \mathrm{C}$ y $21,22^{\circ} \mathrm{C}$ sobre todo en las estaciones del interior de la bahía (Atenas y El Chaco) (Fig. 4a).

La distribución espacial de la temperatura en superficie el 7 de junio (Fig. 6) presentó una tendencia creciente de este a oeste (desde las plantas pesqueras hacia las afueras de la bahía) con isolíneas predominantes de $19^{\circ} \mathrm{C}$. En el fondo, la distribución mostró una tendencia contraria (de $17,0^{\circ} \mathrm{Ca} 15,5^{\circ} \mathrm{C}$ ). Estos patrones indicarían flujos de ingreso de aguas frías por el lado oeste del fondo de la bahía, y flujos de salida por superficie. En junio la ligera elevación de la temperatura habría generado condiciones de estabilidad en la columna de agua.

\section{Oxígeno disuelto}

En el mes de mayo el oxígeno en superficie tuvo un valor mínimo de $0 \mathrm{~mL} . \mathrm{L}^{-1}$ (Est. 6, Plantas Pesqueras) y un máximo de 12,34
mL.L ${ }^{-1}$ (Est. 1, Atenas). Frente a Atenas (Est. 1) y frente al Chaco (Est. 2), zonas próximas a cultivos de concha de abanico, se presentaron valores elevados de oxígeno (75\% de los datos entre $7,5 \mathrm{~mL} . \mathrm{L}^{-1}$ y $12,34 \mathrm{~mL} . \mathrm{L}^{-1}$ ) debido a la presencia de una floración algal nociva (FAN) desarrollada intensamente entre el 22 y 25 de mayo, que elevó los niveles promedio desde 2,77 mL.L ${ }^{-1}$ (17 mayo) a 5,71 mL.L-1 (25 mayo). Las floraciones algales nocivas (FAN), también conocidas como "mareas rojas", son proliferaciones de algas planctónicas que pueden causar un efecto negativo (Hallegraeff 1995).

Entre el 2 y el 9 de junio se observó una tendencia decreciente en las concentraciones de oxígeno, llegando a estados anóxicos en la Est. 2 (Chaco). Los niveles promedio de oxígeno se redujeron de 1,72 (2 junio) a 0,53 mL.L $L^{-1}$ (9 junio) (Fig. 4b).

El 7 de junio, la distribución espacial del oxígeno y el pH en superficie (Figs. 6, 7 y 8) fue similar a la desarrollada por la temperatu-
Figura. 3. Variación temporal de los promedios mensuales de la temperatura superficial en el área de Pisco durante el 2000.

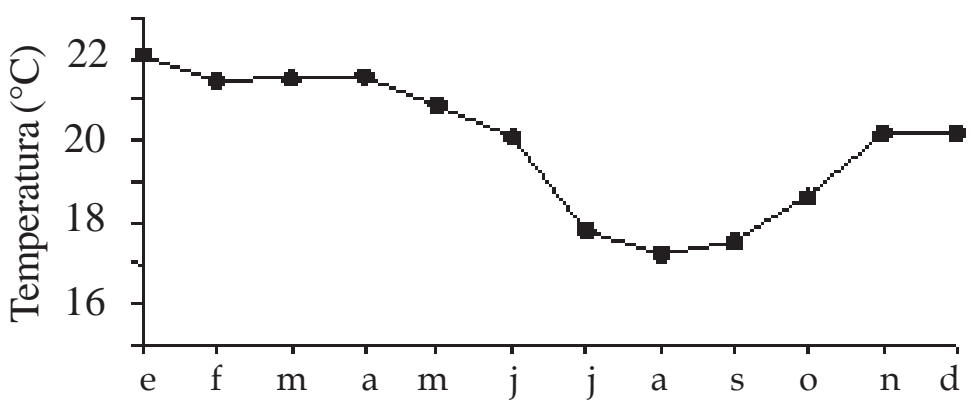



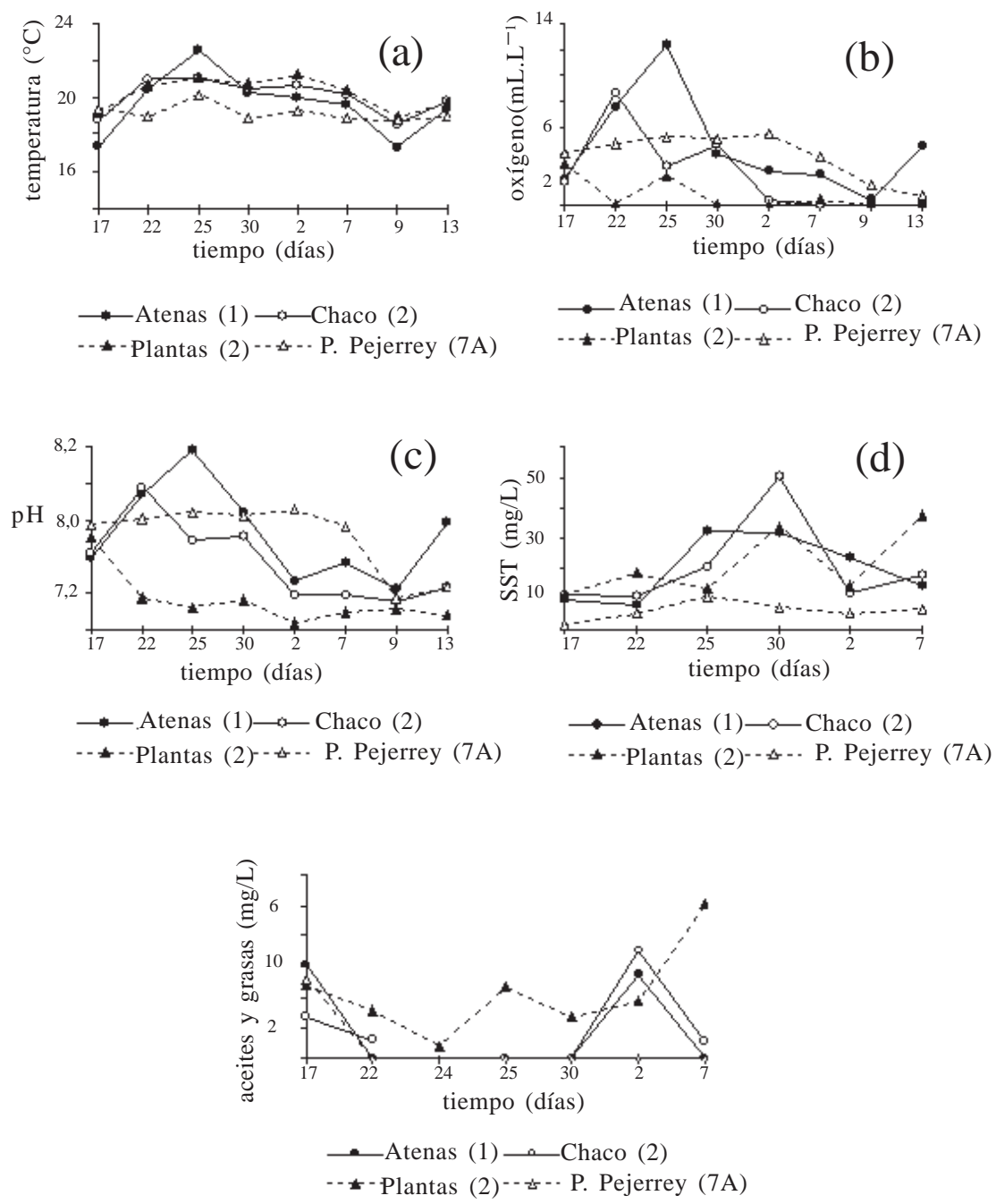

Figura 4. Variables de calidad acuática en superficie en la bahía de Paracas (Pisco), del 17 de mayo al 13 de junio del 2000.

ra, con una tendencia creciente de este a oeste. Frente a las plantas pesqueras (Est. 6) se presentaron condiciones hipóxicas, debido a las descargas periódicas de los efluentes pesqueros, que agotaron el oxígeno por degradación de materia orgánica (Fig. 7).

En el fondo, en mayo el $37,5 \%$ de valores fueron hipóxicos $\left(<1,4 \mathrm{~mL} \cdot \mathrm{L}^{-1}\right)$ y el $37,5 \%$ anóxicos. A partir del 2 de junio, la anoxia en los fondos se prolongó por más de 10 días en el interior de la bahía (Atenas y Chaco).

En áreas someras como Paracas $(<25 \mathrm{~m})$ especialmente frente a Atenas $(<5 \mathrm{~m})$, se esperaría encontrar valores de oxígeno simi- lares en superficie y fondo, sin embargo, se registraron condiciones de hipoxia en fondo $\left(<1,0 \mathrm{~mL} . \mathrm{L}^{-1}\right)$ y valores altos de oxígeno en superficie de hasta $12.34 \mathrm{~mL} . \mathrm{L}^{-1}$. Estas condiciones se deberían tanto a la carga orgánica acumulada durante años en los fondos, como a la actual contaminación orgánica de las descargas pesqueras y el fitodetritus proveniente de la floración algal nociva.

\section{Potencial de iones hidronio $(\mathrm{pH})$}

Los valores de $\mathrm{pH}$ se encontraron en el rango permisible $(6,0-8,5)$ para las Clases IV y V según la Ley General de Aguas $(E l P e$ ruano 1969); sin embargo, en mayo el $81 \%$ de 
Tabla 2. Resultados de los análisis de coliformes termotolerantes y demanda bioquímica de oxígeno $\left(\mathrm{DBO}_{5}\right)$, en las estaciones de estudio de la Bahía de Paracas (Pisco).

\begin{tabular}{cccc}
\hline $\begin{array}{c}\text { Fecha } \\
\text { Muestreo }\end{array}$ & Estación & $\begin{array}{c}\text { Coliformes } \\
\text { Termotolerantes } \\
\text { NMP.(100mL })^{-1}\end{array}$ & $\begin{array}{c}\mathrm{DBO}_{5} \\
\left(\mathrm{mg}^{-1} \mathrm{~L}^{-1}\right.\end{array}$ \\
\hline \multicolumn{4}{c}{ Mar } \\
\hline $02 / 06 / 00$ & Atenas (1) & --- & 9.86 \\
$02 / 06 / 00$ & Chaco (2) & $<30$ & 8.51 \\
$02 / 06 / 00$ & Chaco (2A) & -- & 11,77 \\
$02 / 06 / 00$ & Plantas (6) & $<30$ & 23,83 \\
\hline \multicolumn{5}{c}{ Playa } \\
\hline $01 / 06 / 00$ & H. Paracas (MP) & $<30$ \\
$02 / 06 / 00$ & Plantas (4B) & $4,3 \times 10^{3}$ & 8,40 \\
\hline
\end{tabular}

valores en superficie fueron mayores de 7,5 y en junio este porcentaje disminuyó a sólo $24 \%$, junto con el agotamiento del oxígeno y el consiguiente incremento de sulfuros en fondo (Figs. $4 \mathrm{c}$ y $5 \mathrm{c})$. Los menores valores siempre fueron registrados frente a las plantas pesqueras.

Respecto a la distribución espacial de $\mathrm{pH}$ en superficie, destacó una isolínea de menor $\mathrm{pH}(7,0)$ localizada frente a las plantas pesqueras, asociada al menor contenido de oxígeno (Fig. 8).
Al analizar la base de datos de los monitoreos de calidad acuática desarrollados a lo largo de la costa peruana desde 1994 por el IMARPE, hemos encontrado que valores bajos de pH están asociados a aguas de afloramiento y a contaminación orgánica, especialmente de tipo biodegradable, acompañados de agotamiento de oxígeno que desencadena reacciones de óxido-reducción (M. E. Jacinto, com. pers.).

Tabla 3. Variación diaria de variables físicas y químicas de calidad acuática en playas de la Bahía de Paracas (Pisco), del 17 abril al 13 de junio del 2000.

\begin{tabular}{|c|c|c|c|c|c|c|c|c|c|c|c|c|c|c|}
\hline & \multirow[b]{2}{*}{ días } & \multicolumn{5}{|c|}{ ma yo } & \multicolumn{4}{|c|}{ junio } & \multirow[b]{2}{*}{13} & \multirow[b]{2}{*}{ Prom } & \multirow[b]{2}{*}{ Min } & \multirow[b]{2}{*}{ Max } \\
\hline & & 17 & 22 & 24 & 25 & 30 & 1 & 2 & 7 & 9 & & & & \\
\hline \multirow{4}{*}{ 急 } & Atenas (5A) & 17,5 & 20,6 & 21,7 & 21,5 & 20,3 & & 20,9 & 20,1 & 18,9 & 19,1 & 20,1 & 17,5 & 21,7 \\
\hline & Plantas (4B) & 19,4 & 22,5 & & 23,2 & 20,6 & & 22,2 & 22,5 & 19,4 & 20,9 & 21,3 & 19,4 & 23,2 \\
\hline & H. Paracas (MP) & & & & & & 22,4 & & & & & & & \\
\hline & S. Domingo (E) & & & 22,8 & & & & & & & & & & \\
\hline \multirow{4}{*}{ 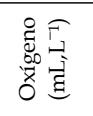 } & Atenas (5A) & 1,99 & 3,06 & 4,54 & 5,48 & 3,88 & & 2,28 & 0,28 & 0,74 & 1,37 & 2,62 & 0,28 & 5,48 \\
\hline & Plantas (4B) & 0,00 & 0,00 & & 0,00 & 3,94 & & 0,17 & 0,17 & 0,00 & 0,00 & 0,54 & 0,00 & 3,94 \\
\hline & H. Paracas (MP) & & & & & & 2,80 & & & & & & & \\
\hline & S. Domingo (E) & & & 3,80 & & & & & & & & & & \\
\hline \multirow{4}{*}{ 兑 } & Atenas $(5 \mathrm{~A})$ & 7,67 & 7,86 & & 8,13 & 7,78 & & 7,44 & 7,29 & 7,21 & 7,53 & 7,61 & 7,21 & 8,13 \\
\hline & Plantas (4B) & 7,12 & 7,09 & & 7,12 & 7,40 & & 6,83 & 6,98 & 6,95 & 6,98 & 7,15 & 6,83 & 7,52 \\
\hline & H. Paracas (MP) & & & & & & 7,72 & & & & & & & \\
\hline & S. Domingo (E) & & & & & & & & & & & & & \\
\hline \multirow{4}{*}{ की } & Atenas $(5 \mathrm{~A})$ & 8,47 & 7,60 & 7,20 & 12,0 & 9,60 & & 13,20 & 12,50 & & & 10,08 & 7,20 & 13,20 \\
\hline & Plantas (4B) & 15,20 & 49,28 & & 14,34 & 23,17 & & 26,42 & 109,76 & & & 39,70 & 14,34 & 109,76 \\
\hline & H. Paracas (MP) & & & & & & & & & & & & & \\
\hline & S. Domingo (E) & & & 29,67 & & & & & & & & & & \\
\hline \multirow{4}{*}{ 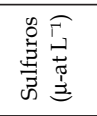 } & Atenas $(5 \mathrm{~A})$ & & 0,42 & & 0,58 & & & & & & & 0,50 & 0,42 & 0,58 \\
\hline & Plantas (4B) & & 13,02 & & 11,75 & 0,80 & & 2,31 & & & & 6,97 & 0,80 & 13,02 \\
\hline & H. Paracas (MP) & & & & & & 1,30 & & & & & & & \\
\hline & S. Domingo (E) & & & & & & & & & & & & & \\
\hline \multirow{4}{*}{ 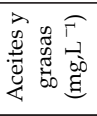 } & Atenas $(5 \mathrm{~A})$ & & & 1,26 & & & & & & & & 1,26 & 1,26 & 1,26 \\
\hline & Plantas (4B) & 5,79 & 11,90 & & 3,89 & 2,40 & & 7,50 & 8,69 & & & 6,70 & 2,40 & 11,90 \\
\hline & H. Paracas (MP) & & & & & & 3,50 & & & & & & & \\
\hline & S. Domingo (E) & & & 1,00 & & & & & & & & & & \\
\hline
\end{tabular}




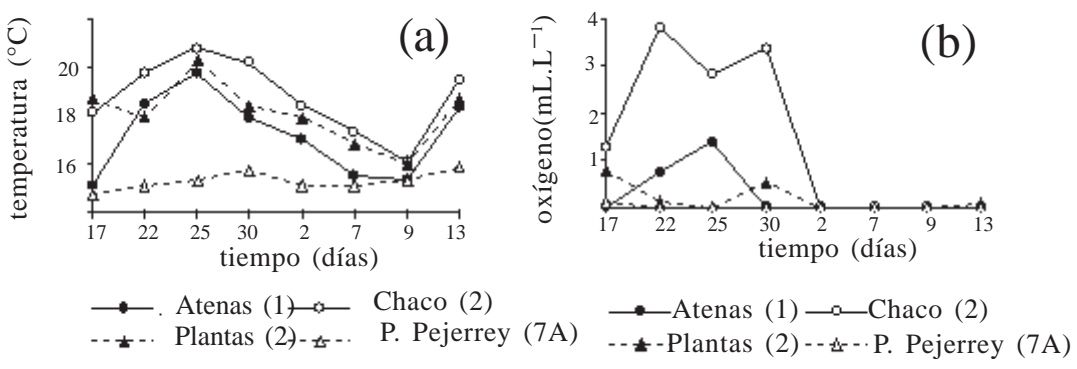

(c)
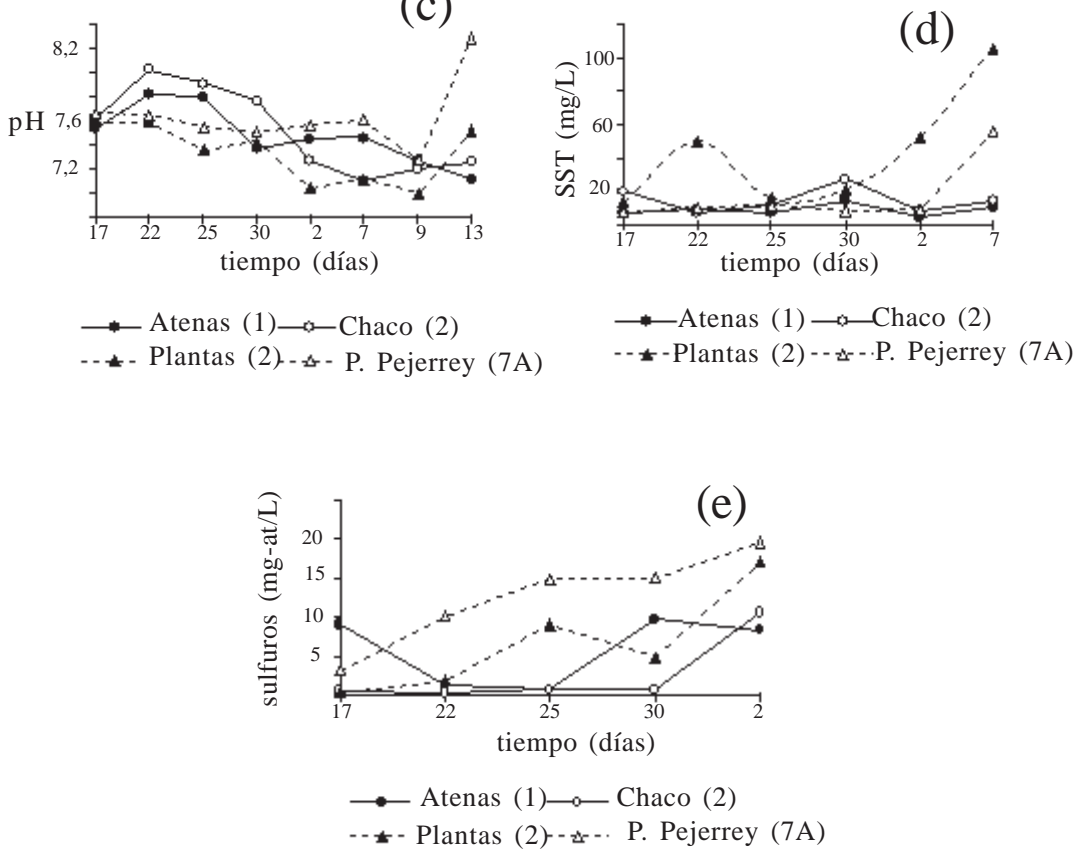

Figura 5. Variables de calidad acuática en fondo en la bahía de Paracas (Pisco), del 17 de mayo al 13 de junio del 2000.

\section{Sólidos suspendidos totales}

Durante la segunda quincena de mayo los sólidos suspendidos en superficie en promedio experimentaron una tendencia creciente desde 8,48 mg. $\mathrm{L}^{-1}$ (17 mayo) hasta 30,64 mg. $\mathrm{L}^{-1}$ (30 mayo). Esta tendencia estuvo asociada al incremento de células fitoplanctónicas provenientes de la floración algal nociva observada desde el 22 de mayo.

La disminución a principios de junio coincidió con la finalización de la marea roja. La zona de Atenas y El Chaco (Est. 1 y 2) presentaron este incremento de sólidos (entre el 25 y 30 de mayo) con valores mayores de $30 \mathrm{mg}$. $\mathrm{L}^{-1}$.
En fondo, en mayo los sólidos suspendidos fluctuaron entre 12,0 (17 mayo) y 19,29 mg. $\mathrm{L}^{-1}$ (22 mayo). En la primera semana de junio los valores se incrementaron notablemente hasta un promedio de 46,28 mg. $\mathrm{L}^{-1}$ destacando un valor alto de $105,74 \mathrm{mg}$. $\mathrm{L}^{-1}$ en la Est. 6 (frente a las plantas pesqueras, 7 junio). Esto indicaría que el fondo marino, bastante somero, recibió desde la superficie no sólo la carga biogénica producida por la floración algal nociva, sino que recibió principalmente material orgánico de las descargas residuales pesqueras, originando una situación crítica en 


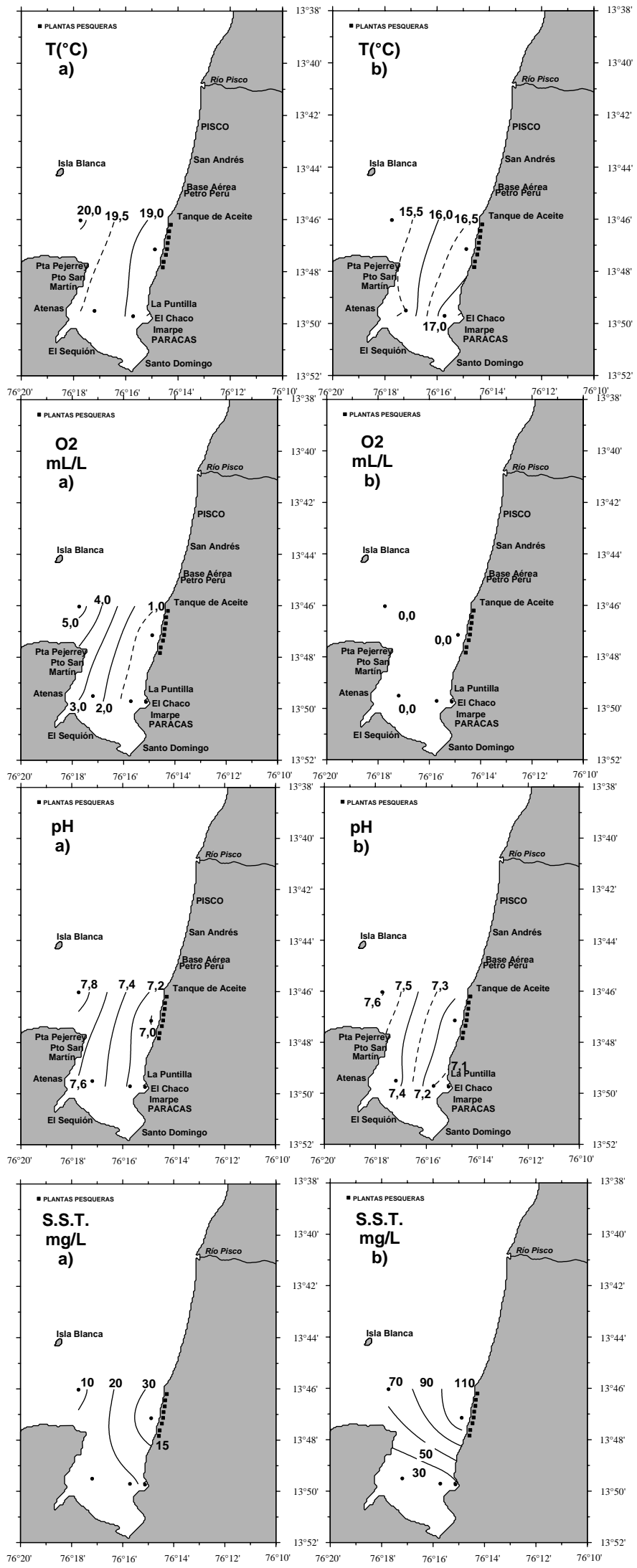

Figura 6. Distribución espacial de la temperatura (a. Superficie, b. Fondo) en la Bahía de Paracas -Pisco, el 7 de junio de 2000.

Figura 7. Distribución espacial del oxígeno (a. Superficie, b. Fondo) en la Bahía de Paracas-Pisco, el 7 de junio de 2000.

Figura 8. Distribución espacial del pH (a. Superficie, b. Fondo) en la Bahía de Paracas-Pisco, el 7 de junio de 2000.

Figura 9. Distribución espacial de sólidos suspendidos (a. Superficie, b. Fondo) en la Bahía de Paracas-Pisco, el 7 de junio de 2000 

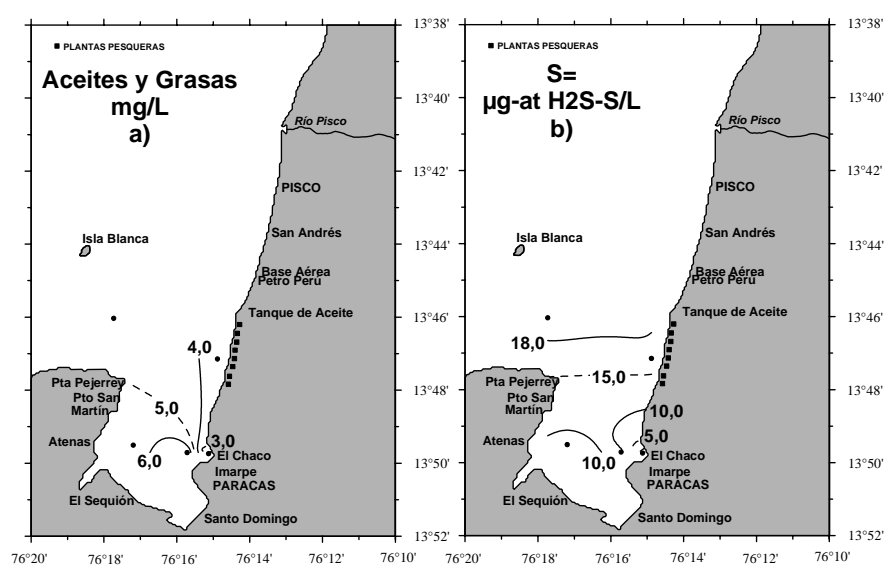

Figura 10. Distribución espacial de a) aceites y grasas (superficie), y b) sulfuros (fondo) en la Bahía de Paracas Pisco, el 7 de junio de 2000. una bahía de extrema sensibilidad, por su morfología cerrada, batimetría somera y baja velocidad de corrientes.

En junio, a pesar de que se registró una menor frecuencia de desembarques, se produjo una varazón de peces el 1 junio frente al hotel Paracas, y luego ocurrió la mortalidad el 6 de junio en Atenas, fechas que coincidieron con desembarques pesqueros elevados. Esta situación puede interpretarse como una sobresaturación de la limitada capacidad asimilativa de carga orgánica por el ecosistema, que se tradujo en condiciones anóxicas intensas que se mantuvieron durante casi 2 semanas. Si bien el sistema pelágico se recupera relativamente rápido conforme el flujo de corrientes renueva las condiciones de la columna de agua, el sistema bentónico requerirá de mucho más tiempo para recuperarse, incluso si se suspende el vertido de efluentes a la bahía.

La distribución espacial de los sólidos suspendidos (Fig. 9) muestra claramente que la principal fuente de sólidos suspendidos son las plantas pesqueras. Cabe destacar que en superficie los valores mayores a 30 mg. $\mathrm{L}^{-1}$ se encuentran frente a las plantas pesqueras y cubren menos de la cuarta parte del área de la bahía; en cambio en el fondo, los valores mayores a $30 \mathrm{mg}$. $\mathrm{L}^{-1}$ ocupan más de la mitad del área de la bahía, lo que genera condiciones de hipoxia o anoxia.

\section{Fitoplancton}

Entre el 22 de mayo y el 2 de junio se observó la presencia de una floración algal nociva o "marea roja" causada por el dinoflagelado Prorocentrum micans, que estuvo presente antes y durante el evento de mortandad (Fig. 11). Esta floración algal estuvo asociada a un ligero incremento de la temperatura, y generó altas concentraciones de oxígeno en toda la bahía, a excepción de la estación correspondiente a las plantas pesqueras (Est. 6).

La formación de una floración algal nociva o "marea roja" requiere de ciertas condiciones favorables para su proliferación: altas temperaturas, altos niveles de intensidad luminosa, estabilidad de la columna de agua y aporte de nutrientes (Margalef 1986), condiciones que estuvieron presentes a fines de mayo.

Los volúmenes de fitoplancton (Fig. 12) mostraron altos valores, especialmente del 22 al 25 de mayo, con una tendencia decreciente a inicios de junio (Laboratorio Costero Pisco 2000b), de manera similar a lo observado con los sólidos suspendidos. A principios de junio la disminución de temperatura coincidió con la desaparición de la marea roja.

Altos valores de materia orgánica (> 5\%) han sido encontrados en los fondos de la bahía de Paracas, frente a las plantas pesqueras (Velazco 2000), lo cual evidencia un proceso de eutrofización que podría estimular un aumento en la frecuencia de mareas rojas en el área. Este proceso de eutrofización 


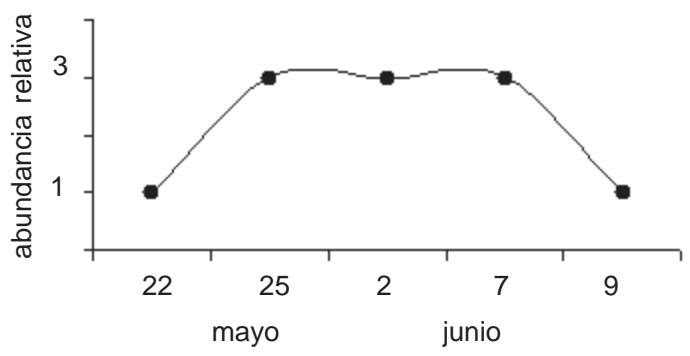

Figura 11. Abundancia cualitativa de Prorocentrum micans en la Bahía de Paracas. Escala: 0 = ausente, 1 = escaso, 2 = regular, 3 = abundante, $4=$ muy abundante (Fuente: Lab. Costero de Pisco).

antropogénica ya ha ocurrido en otros países, provocando un aumento en la frecuencia de floraciones algales nocivas, estimuladas por el vertido de desechos domésticos, industriales y agrícolas (Hallegraeff 1995).

\section{Aceites y grasas}

En superficie las concentraciones de aceites y grasas variaron entre $0,8 \mathrm{mg} . \mathrm{L}^{-1}$ (Est. 6, 24 de mayo) y 10,1 mg.L $\mathrm{L}^{-1}$ (Est. 6, 7 de junio) con un promedio general de 4,12 mg. $\mathrm{L}^{-1}$ (Fig. 4e). Los niveles de aceites y grasas, indicadores de desechos del procesamiento industrial de plantas pesqueras, presentaron valores máximos los días 17 de mayo y 2 de junio, frente a Atenas y El Chaco (Est. 1 y 2).

Desde el 30 de mayo, el incremento de los promedios de aceites y grasas produjo la disminución de oxígeno, y el estado anóxico produjo el incremento de sulfuros en fondo.

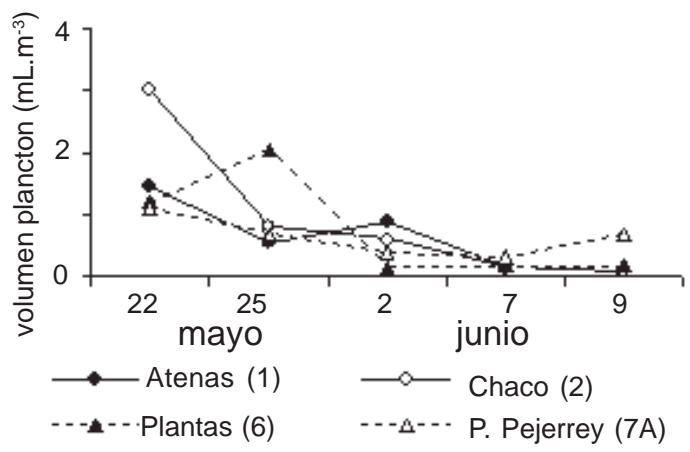

Figura 12. Variación temporal del volumen de plancton. Fuente: Lab. Costero de Pisco.
El incremento de aceites y grasas registró su máximo el 7 de junio en la Est. 6 (10,1 mg. $\mathrm{L}^{-1}$ ), un día después del evento de mortalidad, y estuvo relacionado con los días de mayor desembarque y por ende con un mayor contenido graso en el área de influencia de las descargas residuales, agudizando las condiciones críticas previas que imperaban en el área.

\section{Sulfuros}

Las concentraciones de sulfuros cerca del fondo variaron entre $0,5 \mathrm{ug}$-at $\mathrm{H}_{2} \mathrm{~S}-\mathrm{S}$. $\mathrm{L}^{-1}$ (Est. 6, 17 de mayo) y 19,73 ug-at $\mathrm{H}_{2}$ S-S.L ${ }^{-1}$ (Est. 7A, 2 de junio) con un promedio general de 6,86 ug-at $\mathrm{H}_{2}$ S-S.L-1 (Fig. 5e).

Los promedios diarios de sulfuros entre el 17 y 22 de mayo alcanzaron los 3,5 ug-at $\mathrm{H}_{2} \mathrm{~S}$ $\mathrm{S}$. $\mathrm{L}^{-1}$, y estuvieron asociados a valores de oxígeno hipóxicos en el fondo $\left(<1.2 \mathrm{~mL} . \mathrm{L}^{-1}\right)$. A partir del 25 de mayo se incrementaron fuertemente los sulfuros (promedio: 6,5 ug-at $\mathrm{H}_{2} \mathrm{~S}$ S.L $L^{-1}$ ) hasta el 2 de junio (promedio: 11,9 ug-at $\mathrm{H}_{2} \mathrm{~S}-\mathrm{S}$. $\mathrm{L}^{-1}$ ), debido a procesos de reducción de sulfato. Cabe destacar que los sulfuros son altamente tóxicos para la vida acuática aeróbica, especialmente para los cultivos de concha de abanico en la zona de Atenas.

\section{Coliformes termotolerantes}

Los resultados de la evaluación realizada el 2 de junio indicaron que las concentraciones de coliformes termotolerantes frente a $\mathrm{El} \mathrm{Chaco}$ (Est. 2) y las plantas pesqueras (Est. 6) fueron menores de 30 NMP. $(100 \mathrm{~mL})^{-1}$ (Tabla 2). Esto significa que no hubo influencia de descargas domésticas en la bahía, y los coliformes estuvieron dentro del rango permisible de la Ley General de Aguas para las Clases IV y V (1000 y 200 NMP. (100 mL)-1 respectivamente). Los bajos valores de coliformes coinciden con los valores registrados el 3 de marzo $(<30$ NMP. $\left(100 \mathrm{~mL}^{-1}\right)$ durante otro evento de mortalidad de concha de abanico (Castillo 2000).

\section{Demanda bioquímica de oxígeno $\left(\mathrm{DBO}_{5}\right)$}

La demanda bioquímica de oxígeno el 2 de junio (Tabla 2) varió entre 8,51 mg.L-1 $(\mathrm{El}$ 

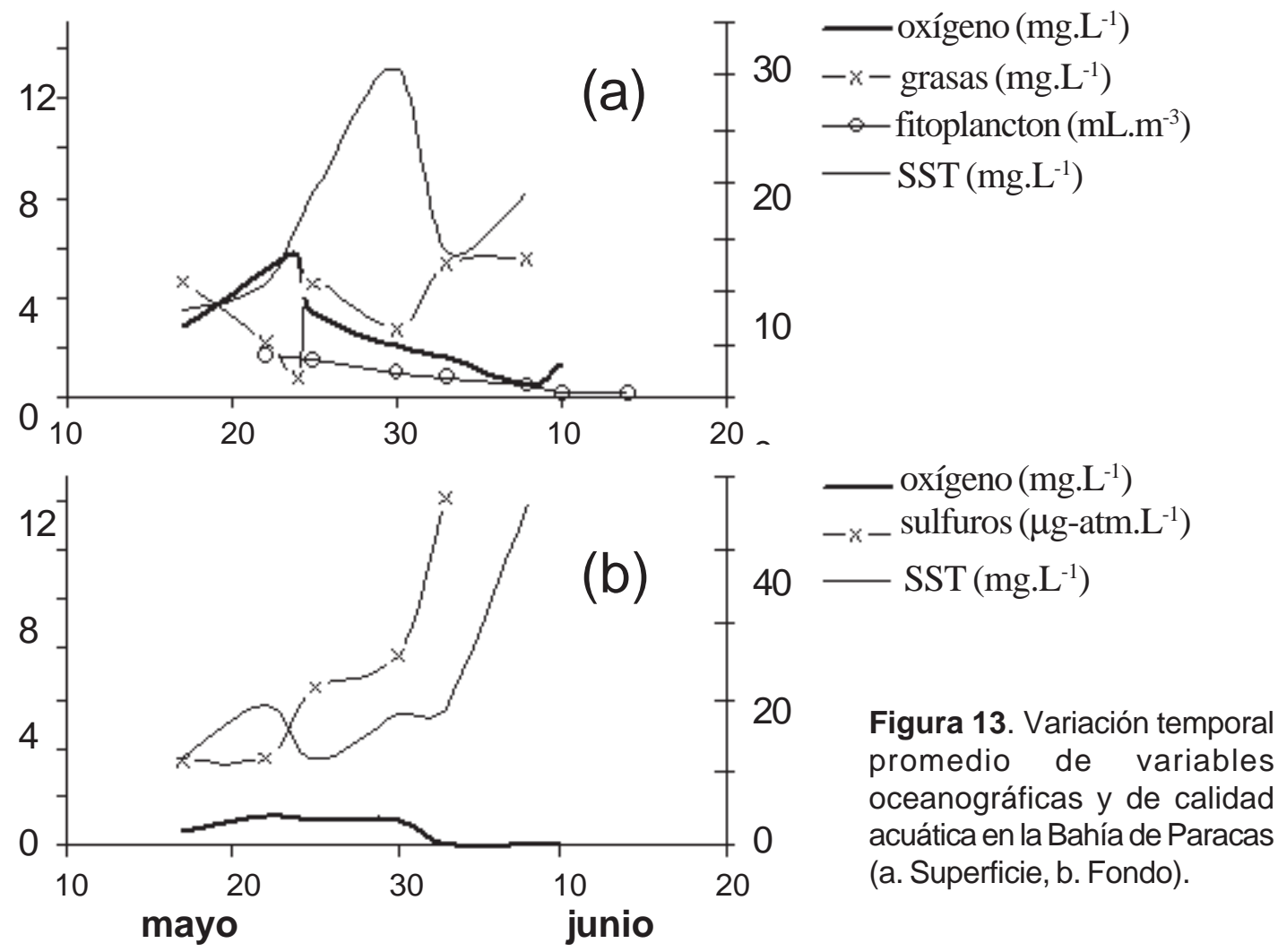

Chaco) y $23,83 \mathrm{mg} \cdot \mathrm{L}^{-1}$ (plantas pesqueras). El máximo valor se presentó frente a las plantas pesqueras y superó los límites establecidos por la Ley General de Aguas (> $\left.10 \mathrm{mg} . \mathrm{L}^{-1}\right)$. Aunque los valores registrados frente a Atenas y El Chaco (Est. 1 y 2) cumplen los estándares de calidad ambiental, fueron relativamente altos en comparación con los períodos sin actividad pesquera $\left(<4,0 \mathrm{mg} \cdot \mathrm{L}^{-1}\right)$.

\section{Evaluación por playas}

La calidad acuática en la zona de playas se evaluó en 4 estaciones (Fig. 14): frente a la playa de Atenas (Est. 5A), en Santo Domingo (Est. E) y frente al hotel Paracas (Est. MP) y frente a las plantas pesqueras (Est. 4B). Los resultados obtenidos durante el período del 17 mayo al 13 de junio del 2000 se presentan en la Tabla 3.

En las estaciones próximas a los cultivos de concha de abanico (Est. 5A, E y MP) las temperaturas variaron de 17,5 a $22,8^{\circ} \mathrm{C}$ y fueron menores a las registradas frente a las plantas pesqueras $\left(19,4\right.$ a $\left.23,2^{\circ} \mathrm{C}\right)$. En Atenas las concentraciones de oxígeno variaron de 0,0 a

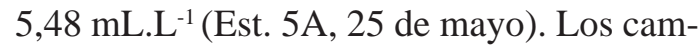
bios de temperatura se relacionaron directamente con las concentraciones de oxígeno (Fig. 14a y 14b), especialmente en Atenas (Est. 5A), mientras que frente a las plantas pesqueras (Est. 4B) se presentaron persistentes condiciones anóxicas, a excepción del día 30 de mayo (3,94 $\left.\mathrm{mL} . \mathrm{L}^{-1}\right)$. El día 7 de junio también se registró una condición anóxica frente a Atenas, asociada a la mortalidad de conchas de abanico.

El contenido de grasas presentó mayor fluctuación y mayores valores frente a las plantas pesqueras (Est. 4B) con valores de 2,4 a 11,9 mg.L $\mathrm{L}^{-1}$, en comparación con Atenas (Est. 5A) con valores menores de 1,5 mg.L L $^{-1}$ (Fig. 14e). 
(a)

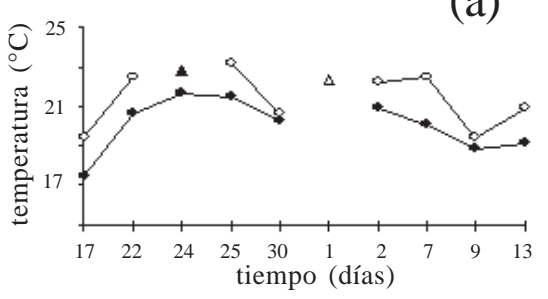

$\longrightarrow$ Atenas $(5 \mathrm{~A}) \_$—Plantas (4B)

- - S. Domingo(E) $-\cdots A^{-\cdots}$ H. Paracas MP)

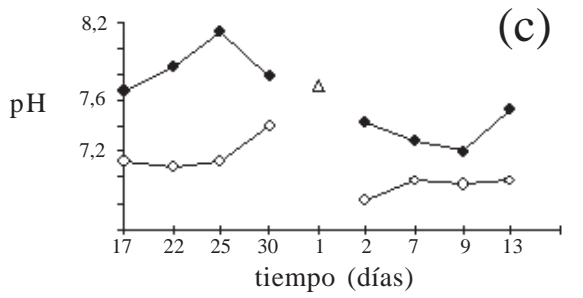

$\longrightarrow$ Atenas $(5 \mathrm{~A}) \longrightarrow$ Plantas $(4 \mathrm{~B})$

- - - - H. Paracas MP)

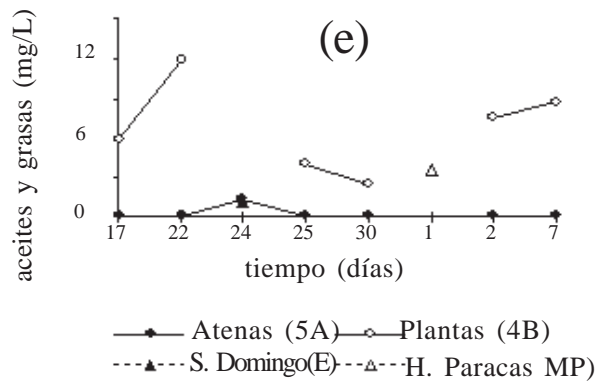

(b)

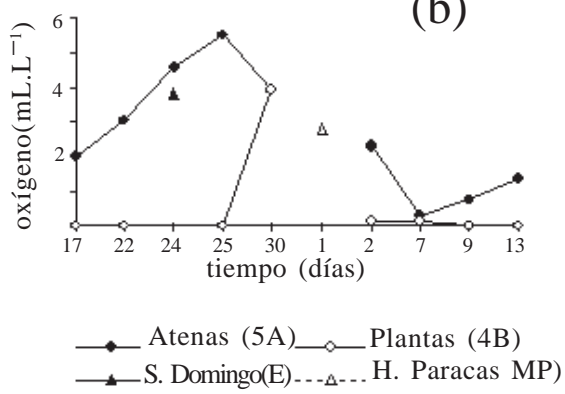

(d)

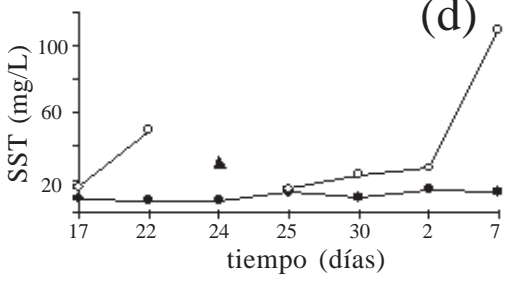

$\longrightarrow$ Atenas (1) —- Chaco (2)

P. Pejerrey (7A)

(f)

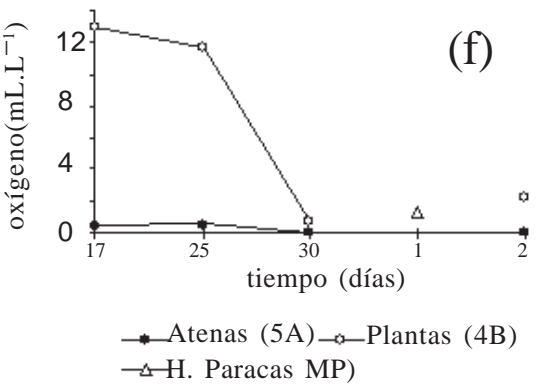

Figura 14. Parámetros químicos de calidad acuática en la zona de playa de la bahía de Paracas (Pisco), del 17 de mayo al 13 de junio del 2000.

\section{Secuencia de procesos naturales y antropogénicos asociados al evento de mortalidad de Argopecten purpuratus}

1. En mayo se produjo un ligero incremento de temperatura a nivel local en la bahía, lo que generó estabilidad de la columna de agua.

2. Los desembarques de mayor tonelaje ocurrieron con mayor frecuencia en el mes de mayo (10 000-13 000 ton), y con menor frecuencia en junio. El contenido de aceites y grasas puede indicar un proceso acumulativo por el vertido de efluentes provenientes del procesamiento de los altos desembarques, que en mayo aún no afectaba de manera determinante los niveles superficiales de oxígeno en la bahía.

3. Factores ambientales favorecieron el desarrollo de una floración algal nociva al interior de la bahía (Fig. 15a), que incrementó el oxígeno a nivel superficial y agregó más sólidos suspendidos a la carga contaminante ya existente, especialmente entre el 22 y 25 de mayo. En el fondo, los sólidos suspendidos presentaron fluctuaciones con promedios diarios menores a $20 \mathrm{mg} . \mathrm{L}^{-1}$, asociados a estados anóxicos y a un incremento de sulfuros (Figs. 15b y 16b). 


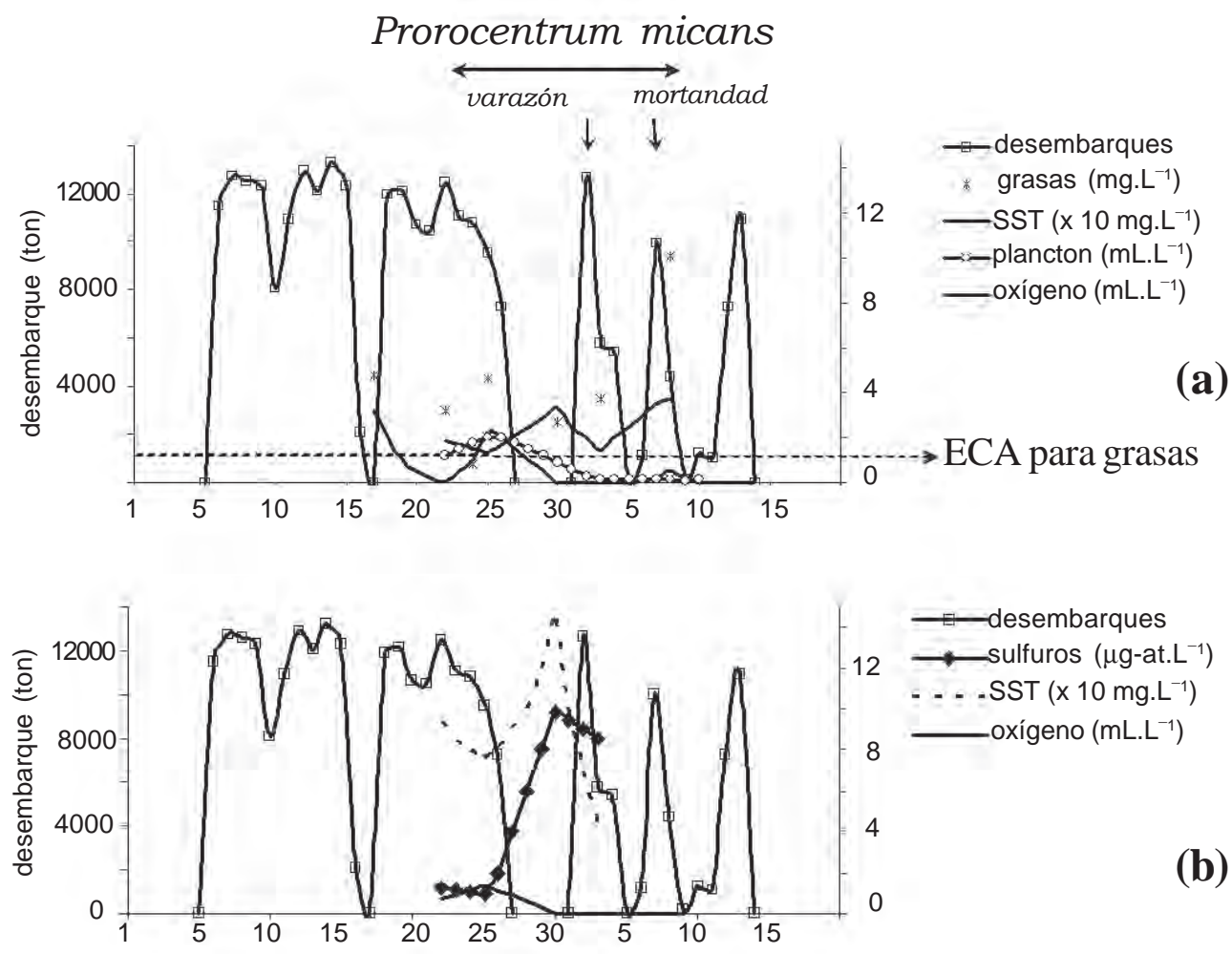

Figura 15. Secuencia de procesos naturales y antropogénicos asociados al evento de mortalidad de concha de abanico frente a las plantas pesqueras (a. Superficie, b. Fondo).

4. A partir del 30 de mayo, se produjo una disminución de los sólidos suspendidos superficiales influenciado por el término de la floración algal nociva. Sin embargo, a partir del 2 de junio, con el reinicio de la actividad pesquera, se produce también un incremento de sólidos suspendidos y aceites y grasas (Fig. 15a). Esta situación generó en el fondo un aumento notable de sólidos suspendidos y un estado anóxico en toda la bahía, con la consiguiente generación de sulfuros tóxicos para la vida acuática (Fig. 16b).

5. Los eventos de varazón (1 junio) y mortandad (6 junio) ocurrieron aproximadamente después de 30 días de iniciada la actividad industrial pesquera.

6. Los procesos naturales y antropogénicos tuvieron un efecto sinérgico sobre el evento de mortalidad de concha de abanico, ya que la carga orgánica que produjo los estados anóxicos provino tanto del fitodetritus de la floración algal nociva como de los efluentes pesqueros. Sin embargo, cabe señalar la posibilidad de un me- canismo causal a largo plazo que produciría una mayor frecuencia de floraciones algales nocivas originada por el incremento de la eutrofización antropogénica (Fig. 17).

\section{Conclusiones}

1. La intensa actividad industrial de las plantas pesqueras conllevó al vertido de grandes cantidades de efluentes al medio marino constituidos por una importante carga orgánica de sólidos suspendidos, aceites y grasas. Este proceso antropogénico junto con el desarrollo de una floración algal nociva, sobresaturó la limitada capacidad asimilativa del ecosistema somero, provocando condiciones críticas que desencadenaron el evento de mortalidad de conchas de abanico frente a la playa Atenas el 6 de junio del 2000.

2. Los procesos naturales y antropogénicos tuvieron un efecto sinérgico sobre el evento de mortalidad de concha de abanico. Sin embargo, el alto contenido de materia orgánica en los se- 


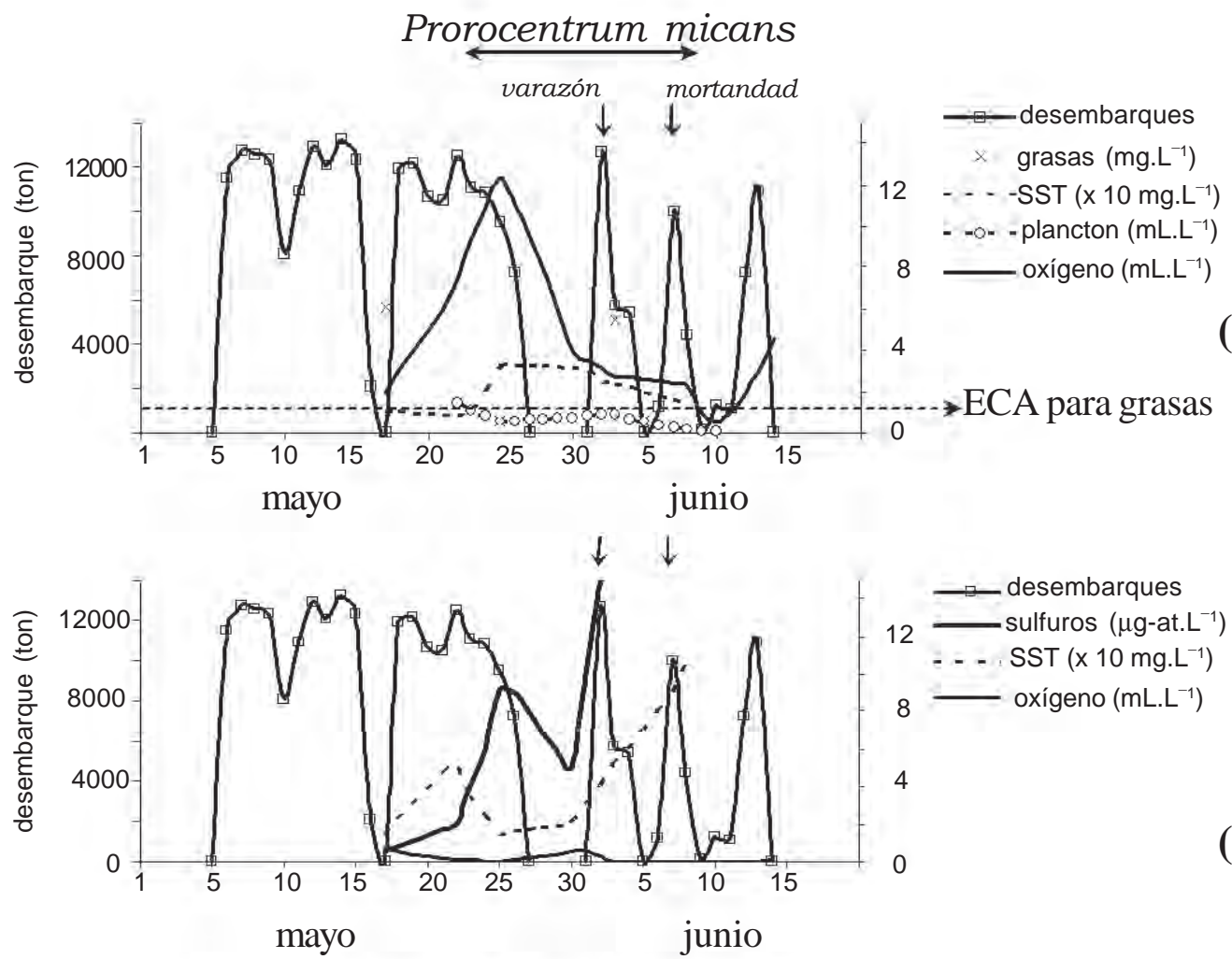

(a)

Figura 16. Secuencia de procesos naturales y antropogénicos asociados al evento de mortalidad de concha de abanico frente a la playa Atenas (a. Superficie, b. Fondo).

dimentos es indicador de un proceso de eutrofización antropogénica de la bahía de Paracas, que podría ocasionar a largo plazo un incremento en la frecuencia de las floraciones algales nocivas.

\section{Recomendaciones}

Se recomienda investigar la posibilidad de implementar vedas para protección del ambiente marino costero, en función de la calidad acuática y sedimentológica de las bahías que reciben efluentes pesqueros.

En caso de establecer una zona de impacto pesquero se debe investigar su superficie máxima, que no debiera exceder más de la cuarta parte del área de la bahía, de modo que las isolíneas correspondientes a los estándares de calidad ambiental (e. g. 35 mg.L $\mathrm{L}^{-1}$ en el caso de sólidos suspendidos) no superen dicha extensión tanto en la superficie como en el fondo.
Se debe promover e incentivar el uso de tecnologías limpias en la industria pesquera (bombas de vacío, plantas evaporadoras de agua de cola), tecnología que debe ser complementada con una adecuada preservación de la calidad de la materia prima y con una disposición adecuada de residuos líquidos y sólidos (vertido de agua de bombeo por emisores submarinos fuera de la bahía, tratamiento biológico del agua de bombeo, uso de residuos sólidos como fertilizantes, etc.).

Las medidas ambientales que se tomen en el futuro permitirían investigar también relaciones causales entre reducciones de carga orgánica y disminución de eventos de mortalidad (Reckhow 1999).

\section{Agradecimientos}

Al personal del Laboratorio Costero de Pisco de IMARPE, por haber facilitado información sobre las condiciones ambientales y desembarques de la zona de Pisco. 


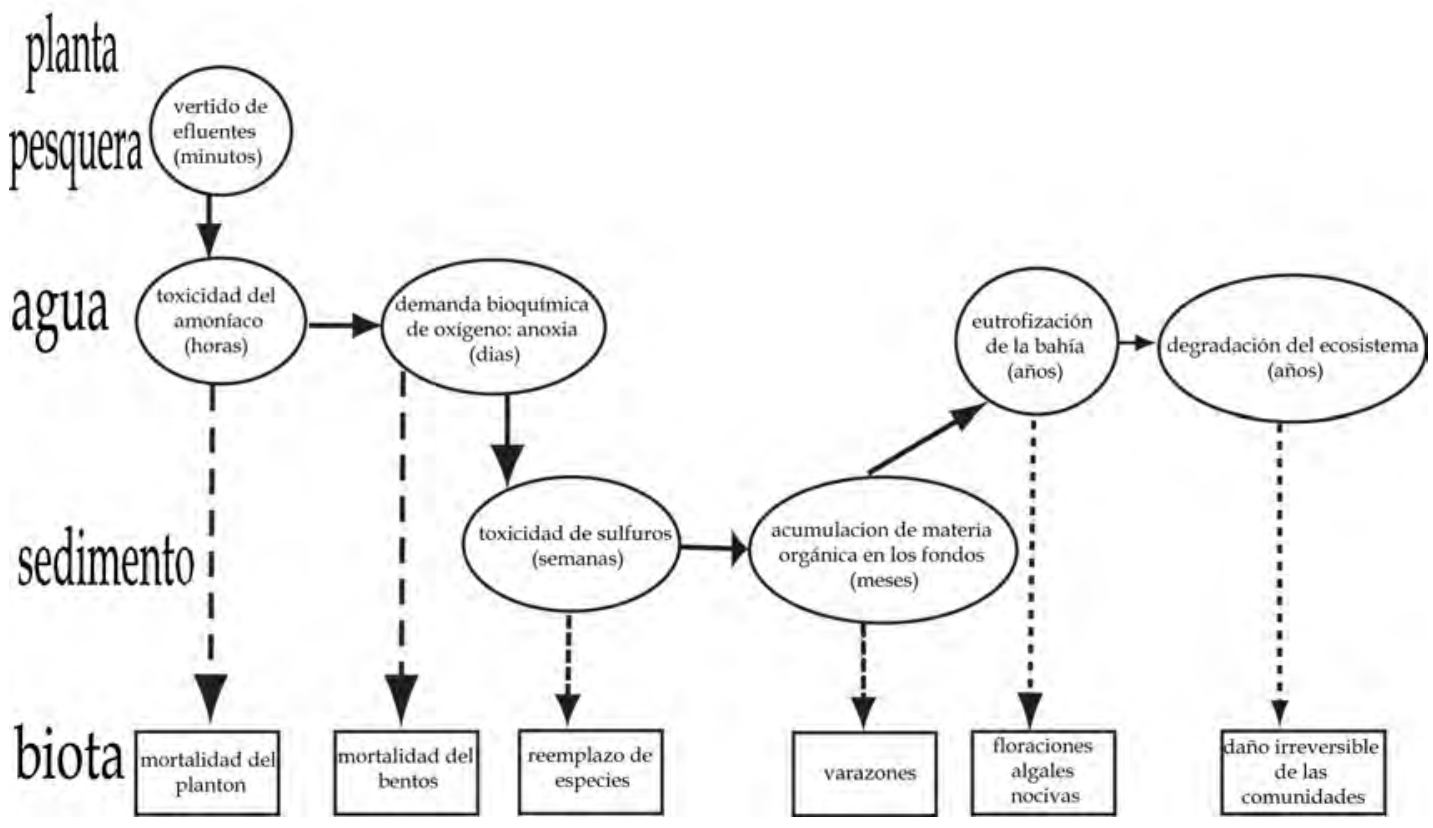

Figura. 17. Escalas temporales de los efectos del vertido de efluentes pesqueros en el medio marino.

\section{Literatura citada}

APHA-AWWA-WPCF. 1999. Standard methods for the examination of water and wastewater. 20th Ed. New York.

Área de Evaluación de la Contaminación Marina. Base de datos de parámetros físicos y químicos de calidad acuática a lo largo de la costa peruana.

Cabello, R. y S. Castillo. 2000. Varazón de peces en la Bahía Paracas (01/06/2000). Evaluación de la calidad acuática marina (mayo-07 junio 2000) durante el período industrial pesquero. Inf. Int. Inst. Mar Perú.

Castillo, S. 2000. Informe sobre evaluación de la calidad acuática en la bahía Paracas-Pisco el día 03/03 del 2000. Inf. Int. Inst. Mar Perú.

El Peruano. 1969. Ley General de Aguas. D. L. 17752.

Environmental Laboratory Water Resources Service. 1976. A laboratory manual for the chemical analysis of waters, wastewaters sediments and biological tissues. Second edition. Vancouver, B.C.

Grados, C., M. Jacinto y E. Carcamo. 1994. Varazón de peces en Pisco (6 enero 1994). Inf. Int. Inst. Mar Perú.

Grasshoff, K. 1999. Methods of seawater Analysis. Verlag Chemie. New York.

GS (Golden Software). 1999. SURFER version 7.00. User's Manual.

Hallegraeff, G. 1995. Harmful algal blooms: a global overview. P. 1-22. In: Hallegraeff, G., D.
Anderson and A. Cembella (eds.). Manual of harmful marine microalgae. IOC Manual and Guides (33):551 pp.

International Standard. 1983. Water quality deterioration of biochemical oxygen demand aftern day (BODn)- Dilution and seeding method. ISO 5815. International Estándar. 12 pp.

Jacinto, M., C. Martínez, S. Sánchez, G. Flores y L. Pizarro. 1996. Evaluación de la varazón y contaminación en la Bahía de Paracas-Pisco. Inf. Prog. Inst. Mar Perú. (29):3-46 pp.

Laboratorio Costero de Pisco. 2000a. Varazón ocurrida frente al Hotel Paracas en la Bahía de ParacasPisco (01/06/2000). Inf. Int. Inst. Mar Perú.

Laboratorio Costero de Pisco. 2000b. Monitoreo ambiental marino en la bahía de Paracas-Pisco. Comunidad fitoplanctónica (22 mayo-9 junio). Inf. Int. Inst. Mar Perú.

Margalef, R. 1986. Ecología. Ed. Omega. España. 950 pp. Reckhow, K. K. 1999. Water quality prediction and probability network models. Can. J. Fish. Aquat. Sci. 56:1150-1158.

Sánchez, G. y A. Lorenzo. 2000. Informe de la situación del ambiente marino en las bahías de Pisco y Paracas. 07 y 08 de Abril de 2000. Inf. Int. Inst. Mar Perú.

Sournia, A. 1978. Phytoplankton manual. UNESCO. París. Velazco, F. 2000. Distribución de materia orgánica en sedimentos de la bahía de Paracas-Pisco. Inf. Int. Inst. Mar Perú. 